\title{
The Effect of Fertilization and Mycorrhiza on Cadmium Uptake by Tobacco*
}

\author{
by \\ M. Janoušková ${ }^{1}$, N. Lugon-Moulin ${ }^{2}$, F. Martin ${ }^{2}$, and M. Vosátka ${ }^{1}$ \\ ${ }^{1}$ Department of Mycorrhizal Symbioses, Institute of Botany, Academy of Sciences of the Czech Republic, \\ 25243 Průhonice, Czech Republic \\ ${ }^{2}$ Philip Morris International R\&D, c/o Philip Morris Products SA, 2000 Neuchâtel, Switzerland
}

\section{SUMMARY}

The effect of fertilization and arbuscular mycorrhiza (AM) on cadmium $(\mathrm{Cd})$ uptake by tobacco (Nicotiana tabacum L.) was studied in a greenhouse pot experiment. Two tobacco varieties and five AM fungal isolates were included in this study. Each combination of tobacco variety $\times$ AM fungal isolate was compared in two fertilization treatments: a nutrient solution and a slow-release fertilizer. Unexpectedly, root colonisation levels were low for most treatments. They were lower in the treatments having received the slow-release fertilizer than in the treatments with the nutrient solution. Inoculation with two AM fungal isolates led to a significant reduction of the $\mathrm{Cd}$ concentration in tobacco leaves. However, the main outcome of this study was the important effect of the fertilization regime on the $\mathrm{Cd}$ concentration of tobacco leaves. For one variety, $\mathrm{Cd}$ concentration was decreased by $48-58 \%$ in the slow-release fertilizer treatment when compared to the nutrient solution treatment. The effect of the fertilization regime on leaf $\mathrm{Cd}$ concentration was thus clearly more pronounced than that of AM. Similar results were obtained for the other variety, although the decrease was less pronounced. [Beitr. Tabakforsch. Int. 23 (2009) 244-247]

\section{ZUSAMMENFASSUNG}

Der Einfluss von Düngung und arbuskulärer Mykorhiza (AM) auf die Cadmiumaufnahme von Tabak (Nicotiana tabacum L.) wurde in einem Gefäßexperiment im Gewächshaus untersucht. Die Studie umfasste zwei Tabaksorten und fünf Isolate von AM Pilzen. Jede Kombination von Tabaksorte und AM Pilzisolat wurde in zwei Düngungsvarianten kultiviert: mit Nährlösung und mit
Langzeitdünger. Entgegen ursprünglicher Erwartung hatte die Inokulation mit AM Pilzen nur niedrige Kolonisierung der Tabakwurzeln zur Folge. Die Kolonisierung war niedriger in den Varianten mit Langzeitdünger als in den mit Nährlösung. Inokulation mit zwei der fünf AM Pilzisolate bewirkte eine signifikante Verringerung der Cadmiumkonzentration in den Tabakblättern. Das wichtigste Ergebnis der Studie war jedoch die ausgeprägte Einwirkung der Düngung auf die Cadmiumkonzentration in den Tabakblättern. In einer der zwei untersuchten Tabaksorten war die Cadmiumkonzentration um 48-58\% niedriger mit Langzeitdünger als mit Nährlösung. Die Wirkung der Düngung war somit eindeutig bedeutsamer als die der Inokulation mit AM Pilzen. Für die zweite Tabaksorte wurden ähnliche Ergebnisse erzielt, die Reduktion war jedoch weniger ausgeprägt. [Beitr. Tabakforsch. Int. 23 (2009) 244-247]

\section{RESUME}

Dans une expérience en pot réalisée en serre, nous avons étudié l'effet que l'ajout d'engrais et de mycorhizes arbusculaires (MA) avait sur la prise de cadmium (Cd) par le tabac (Nicotiana tabacum L.). Deux variétés de tabac et cinq isolats MA furent inclus dans cette étude. Chaque combinaison variété de tabac $\times$ isolat MA fut soumise à deux régimes de fertilisation: une solution nutritive et un engrais à libération lente. La colonisation des racines par les mycorhizes demeura faible dans la plupart des traitements. Elle fut moindre dans les traitements ayant reçu l'engrais à libération lente que dans ceux ayant reçu la solution nutritive. Une baisse significative de la concentration en Cd des feuilles fut observée suite à l'inoculation de deux isolats MA. Cependant, le résultat principal de 
cette étude fut l'effet important du régime de fertilisation sur la teneur en $\mathrm{Cd}$ des feuilles de tabac. Pour l'une des deux variétés étudiées, la concentration en Cd fut réduite de 48 à $58 \%$ dans les traitements ayant reçu l'engrais à libération lente par rapport à ceux ayant reçu la solution nutritive. Le type d'engrais administré joua clairement un rôle plus important que celui des mycorhizes sur la teneur en $\mathrm{Cd}$ des feuilles. Des résultats semblables, bien que moins prononcés, furent obtenus pour la seconde variété. [Beitr. Tabakforsch. Int. 23 (2009) 244-247]

\section{INTRODUCTION}

Arbuscular mycorrhiza (AM) not only influences the acquisition of immobile nutrients by plants, but also the uptake of non-essential heavy metals such as cadmium $(\mathrm{Cd})$ (1). In a previous study, several AM fungal isolates were tested for their ability to decrease the $\mathrm{Cd}$ concentration in the leaves of tobacco (Nicotiana tabacum L.) grown in pots containing soils from tobacco fields with $\mathrm{Cd}$ availability at background level (2). In that study, some AM fungal isolates significantly decreased $\mathrm{Cd}$ uptake by tobacco, but most of the tested isolates only poorly colonised the roots of tobacco. This may have been caused by fertilization with soluble $\mathrm{P}$ and $\mathrm{N}$ as high levels of these nutrients can inhibit the development of AM symbiosis $(3,4)$. The goal of the present study was to test the same fertilization regime against a slow-release fertilizer to assess the potential inhibitory effects of the applied nutrient solution. Two effective AM fungal isolates from the previous study and three previously not tested isolates were included into the experiment to assess their ability to colonise the roots of two tobacco varieties and their potential to affect $\mathrm{Cd}$ concentrations in tobacco leaves.

\section{MATERIAL AND METHODS}

Two tobacco (Nicotiana tabacum L.) varieties, K326 and TN90, representing the tobacco types flue-cured and burley, respectively, were each grown in a soil obtained from a field where they had been produced previously (for origin and characteristics of the soils (2). The total amounts of $\mathrm{Cd}$ and $\mathrm{Cd}$ bioavailabilities, estimated by extraction with $0.01 \mathrm{M} \mathrm{CaCl}_{2}$, were similar in these soils (2). The soils had been sterilised by $\gamma$-irradiation prior to use.

Non-mycorrhizal tobacco was compared with tobacco inoculated with one of five AM fungal isolates (isolate name in parentheses): Glomus intraradices Schenck \& Smith (PH5) and G. mosseae (Nicol. \& Gerd.) Gerd. \& Trappe (BEG25) were the two isolates that induced the most pronounced effects on Cd concentrations in tobacco leaves in a previous study (2). G. intraradices (ISRAEL), G. mosseae (NH10), and G. geosporum (Nicol. \& Gerd.) Walker (BEG11) had not been tested in the previous study. Each combination of tobacco variety and inoculation was compared in two fertilization treatments: a) Nutrient solution containing $\left(\mathrm{g} \mathrm{L}^{-1}\right) 1 \mathrm{Ca}\left(\mathrm{NO}_{3}\right)_{2}, 2.5 \mathrm{MgSO}_{4}, 2.5 \mathrm{KCl}$ and $0.25 \mathrm{~g} \mathrm{KH}_{2} \mathrm{PO}_{4}$ for $\mathrm{K} 326$; and the same nutrient concentrations multiplied by 1.5 for TN90. The application of the nutrient solutions started 2 weeks after planting with $100 \mathrm{~mL}$ per week and continued with $200 \mathrm{~mL}$ per week from the $5^{\text {th }}$ week onwards. In total, $\mathrm{N}$ and $\mathrm{P}$ were added in the amounts of $0.21 \mathrm{~g}$ and $0.10 \mathrm{~g}(\mathrm{~K} 326)$, and of $0.32 \mathrm{~g}$ and $0.15 \mathrm{~g}$ (TN90), respectively. b) Slow-release fertilizer Osmocote Exact (Scotts), mixed into the whole soil volume at planting. The dosage was the same for both tobacco types and corresponded to the recommendations of the producer for normal feeding: $3 \mathrm{~g} \mathrm{~L}^{-1}$ soil $(7.5 \mathrm{~g}$ per whole pot volume), 1:1 mixture of 3-4 M Standard and 5-6 M Standard. In total, $\mathrm{N}$ and $\mathrm{P}$ were added in the amounts of $1.16 \mathrm{~g}$ and $0.33 \mathrm{~g}$ in these treatments, respectively. There were 6 replicates for each treatment, 144 plants in total.

The preparation of the tobacco seedlings and inoculum as well as the planting of the experiment followed JANOUŠKOVÁ et al. (2). Harvesting took place 12 weeks after planting. Mid-stalk position leaves (number 7-12) were oven-dried $\left(80{ }^{\circ} \mathrm{C}\right)$, ground and analyzed for their concentrations of $\mathrm{Cd}$. To evaluate the intraradical development of AM fungi, three soil cores were taken from the pots, pooled and used to extract roots for the estimation of root colonisation by the AM fungi (for further details of all methods see (2). Root colonisation was evaluated using the grid-line intersect method (5), counting 100 intersections. When no positive count was made, but root colonisation was found in the root sample, it was expressed as $<1 \%$. The effects of variety, inoculation and fertilisation on root colonisation where evaluated by three-way analysis of variance ANOVA assigning colonisation of 0 to the replicates with $<1 \%$ of root colonisation.

Data on Cd concentration and biomass were statistically analyzed for each variety separately by two-way ANOVA with the factors inoculation and fertilization. One-sided Dunnett's test (6) at $P=0.05$ was used to compare the inoculated treatments to the control non-mycorrhizal treatment for each combination of variety and fertilization separately.

\section{RESULTS}

\section{Root colonisation}

Unexpectedly, there were low root colonisation levels of $<1 \%$ in most treatments following inoculation with AM fungi. K326 had higher average colonisation levels only when inoculated with BEG11 and receiving nutrient solution $(17 \%)$, TN90 when inoculated with PH5 and ISRAEL (nutrient solution, 6 and 13\%, respectively) and with BEG11 (nutrient solution and slow-release fertilizer, 34 and 25\%, respectively). Root colonisation was thus significantly dependent on the inoculated isolate $(P<0.001)$, lower in K326 than in TN90 $(P<0.001)$, but also lower in the treatments having received the slow-release fertilizer than in the treatments with nutrient solution $(P<0.001)$.

\section{Effects on biomass}

Inoculation with AM fungi had little effect on the shoot growth of the two tobacco varieties. Plants of both varieties produced more shoot biomass when they were grown with the slow-release fertilizer than when fed with the nutrient solution. The increased shoot biomass was due to increased biomass of stems and flowers as the biomass of leaves did either not differ between the two fertilization treatments (K326) or was even lower with the slow-release fertilizer than with nutrient solution (TN90) (Table 1). 
Table 1: Dry weights of the total shoot biomass and the biomass of leaves of the tobacco varieties K326 and TN90, fertilized with nutrient solution (nutrient sol) or slow-release fertilizer (slow-rel), either non-mycorrhizal (NM) or inoculated with five different AM fungal isolates (PH5, BEG25, Israel, NH10, BEG11). Values are means (SD), those marked with an asterisk are significantly different from the corresponding NM (non-mycorrhizal) treatment according to one-sided Dunnett's test at $P=0.05$ (n.s. = not significant).

\begin{tabular}{|c|c|c|c|c|c|c|c|c|}
\hline \multirow[b]{3}{*}{ Inoculation } & \multicolumn{4}{|c|}{ K326 } & \multicolumn{4}{|c|}{ TN90 } \\
\hline & \multicolumn{2}{|c|}{ Shoots total $(\mathrm{g})$} & \multicolumn{2}{|c|}{ Leaves $(\mathrm{g})$} & \multicolumn{2}{|c|}{ Shoots total $(\mathrm{g})$} & \multicolumn{2}{|c|}{ Leaves $(\mathrm{g})$} \\
\hline & nutrient sol & slow-rel & nutrient sol. & slow-rel & nutrient sol & slow-rel & nutrient sol & slow-rel \\
\hline BEG25 & $45(5)$ & $52(4)$ & $22(3)$ & $21(2)$ & $48(4)$ & $58(4)$ & $27(4)$ & $23(3)$ \\
\hline PH5 & $46(6)$ & $60(3)$ & $25(4)$ & $26(2)$ & *43 (3) & $55(3)$ & $24(3)$ & $24(4)$ \\
\hline Israel & $45(5)$ & 57 (10) & $23(2)$ & $24(5)$ & $52(2)$ & $57(2)$ & $28(1)$ & $26(3)$ \\
\hline $\mathrm{NH} 10$ & $47(3)$ & $52(4)$ & $24(4)$ & $22(2)$ & *45 (4) & $58(4)$ & $25(1)$ & $24(3)$ \\
\hline BEG11 & $43(4)$ & $51(8)$ & $19(1)$ & $21(3)$ & $49(10)$ & $59(10)$ & $27(8)$ & $24(2)$ \\
\hline NM & $45(4)$ & $59(8)$ & $22(2)$ & $22(2)$ & $54(5)$ & $61(5)$ & $30(5)$ & $24(1)$ \\
\hline \multicolumn{9}{|c|}{ Significant effects according to two-way ANOVA } \\
\hline Fertilization (A) & \multicolumn{2}{|c|}{$* \star *(49.02)$} & \multicolumn{2}{|c|}{ n.s. $(0.27)$} & \multicolumn{2}{|c|}{$* \star * *(65.33)$} & \multicolumn{2}{|c|}{${ }^{* *}(10.20)$} \\
\hline Inoculation (B) & \multirow{2}{*}{\multicolumn{2}{|c|}{ n.s. (1.78) }} & \multicolumn{2}{|c|}{${ }^{* \star *}(4.91)$} & \multicolumn{2}{|c|}{${ }^{* *}(3.76)$} & \multicolumn{2}{|c|}{ n.s. (1.78) } \\
\hline$A \times B$ & & & \multicolumn{2}{|c|}{ n.s. (1.03) } & \multicolumn{2}{|c|}{ n.s. (1.22) } & \multicolumn{2}{|c|}{ n.s. (1.20) } \\
\hline
\end{tabular}

$\square$ nutrient solution $\mathbb{Z}$ slow-release fertiliser

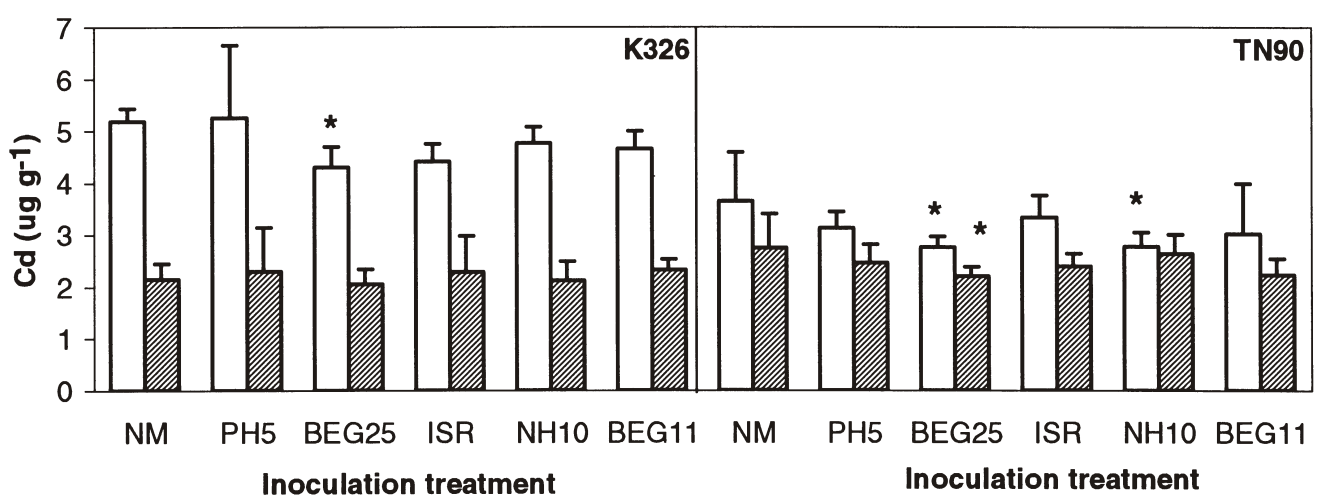

Figure 1. Cadmium concentrations $\left(\mu_{\mathrm{g} \mathrm{g}}{ }^{-1}\right)$ in the middle leaves of the $\mathrm{K} 326$ and TN90 variety of tobacco, fertilized with nutrient solution or slow-release fertilizer, either non-mycorrhizal (NM) or inoculated with five different AM fungal isolates (PH5, BEG25, Israel, NH10, BEG11). Columns represent means (SD), those marked with an asterisk are significantly different from the corresponding NM (non-mycorrhizal) treatment according to one-sided Dunnett's test at $P=0.05$.

\section{Effects of mycorrhiza on Cd concentration in tobacco leaves}

According to two-way ANOVA evaluating the effects of inoculation and fertilization treatment, inoculation significantly affected the Cd concentrations in TN90 $(P=0.03)$, but not in K326. When the effect of inoculation was evaluated for each fertilization treatment separately, inoculation with two AM fungal isolates led to a significant reduction of the Cd concentration in tobacco leaves (Figure 1). The isolate BEG25 showed the most pronounced effect: for TN90, it reduced the average Cd concentration by $24 \%$ (nutrient solution) and 20\% (slow-release fertilizer) when compared with the corresponding non-mycorrhizal controls. For K326, the reduction was significant only in the nutrient solution treatment (by 17\%). Inoculation with isolate NH10 significantly decreased the $\mathrm{Cd}$ leaf concentration in one treatment (TN90, nutrient solution treatment, by $24 \%$ ).

\section{Effects of fertilization on Cd concentration in tobacco leaves}

Fertilization regime significantly affected $\mathrm{Cd}$ concentration of tobacco leaves $(P<0.001$ for both varieties, Figure 1). Cadmium concentration in the leaves of the control K326 was decreased by $58 \%$ in the slow-release fertilizer treatment when compared to the nutrient solution treatment (2.16 vs. $5.19 \mathrm{mg} \mathrm{Cd} \mathrm{kg}{ }^{-1}$ ). This important reduction in $\mathrm{Cd}$ concentration was also observed in the five inoculation treatments of K326 (48-56\% decrease). Similar results were obtained for TN90, although the decrease was less pronounced. The use of the slow-release fertilizer led to a decrease in leaf $\mathrm{Cd}$ concentration of 5-28\% when compared to the corresponding treatments receiving the nutrient solution.

\section{DISCUSSION}

The lower level of root colonisation in K326 compared with TN90 was in accordance with previous results (2). However, the lower root colonisation in treatments with slow-release fertilizer compared with nutrient solution indicated that the poor development of mycorrhiza in the roots of both tobacco varieties was unlikely to be due to the application of the nutrient solution. Other unidentified factors such as inhibitory effects from the soils or low susceptibility of the tobacco varieties to mycorrhiza could be responsible for this result. Similarly as in the previous study (2), symbiosis with isolate BEG25 decreased Cd concentrations in tobacco leaves in the model soils used despite low root colonisation levels. 
The main outcome of this study, however, was the important effect of the fertilization regime on the $\mathrm{Cd}$ concentration of tobacco. For K326, the reduction in leaf $\mathrm{Cd}$ concentration due to the application of slow-release fertilizer was clearly more important than that of mycorrhiza. For TN90, the effect was comparable with that achieved by inoculation with the most effective AM fungal isolates. The reduced Cd concentration in leaves of plants that received the slow-release fertilizer was not due to a $\mathrm{Cd}$ dilution effect, because the leaf biomass was not increased in the corresponding treatments. Furthermore, it was not due to differences in the $\mathrm{Cd}$ content of the fertilizers. Although phosphate fertilizers may contain different levels of $\mathrm{Cd}$ (7), Cd was below detection limits in both fertilizers used in this study (data not shown). Even if the $\mathrm{Cd}$ concentration in these fertilizers equalled the detection limits, and if all the $\mathrm{Cd}$ added through the fertilizers was available for plant uptake and was recovered in the leaves, most of the $\mathrm{Cd}$ in the leaves would still originate from $\mathrm{Cd}$ already present in the soil, not from $\mathrm{Cd}$ in the fertilizers. In a first step, we used average data on leaf biomass and on $\mathrm{Cd}$ concentration in leaves to calculate the quantity of $\mathrm{Cd}$ extracted by leaves for each treatment (we used the $\mathrm{Cd}$ concentration measured in our mid-stalk position leaves for all leaves). In a second step, we calculated the amount of $\mathrm{Cd}$ added by fertilizers in pots for each treatment, provided the $\mathrm{Cd}$ concentration in the fertilizer equalled the limit of detection. Under that scenario, the total $\mathrm{Cd}$ added by the nutrient solution would account for only $5 \%$ of $\mathrm{Cd}$ extracted by K326 leaves, and Cd added by the slowrelease fertilizer, to only $4 \%$; for TN90, the corresponding values would be $10 \%$ and $3 \%$, respectively. Therefore, most of the $\mathrm{Cd}$ reported in leaves would not originate from $\mathrm{Cd}$ added through the fertilizers used in the present study. Another factor, fertilizer-induced differences in soil $\mathrm{pH}$, may explain our results as low $\mathrm{pH}$ usually results in increased $\mathrm{Cd}$ accumulation in tobacco leaves (8). However, contrary to expectations, soil $\mathrm{pH}$ either was the same or lower in the slow-release fertilizer than in the nutrient solution treatment. The average $\mathrm{pH}$ across the six inoculation treatments (one $\mathrm{pH}$ determination per treatment on air-dried soil samples collected at harvesting) were, for the slow-release fertilizer and the nutrient solution treatments: 4.6 and 4.7 (K326), and 4.8 and 5.0 (TN90), indicating that soil $\mathrm{pH}$ was probably not responsible for the differences in the $\mathrm{Cd}$ concentrations in the leaves.

The reduced $\mathrm{Cd}$ concentration in the leaves of the plants that received the slow-release fertilizer may be due to fertilizer-induced differences in plant development and metabolism. Indeed, a possible explanation is that more $\mathrm{Cd}$ was trapped in the stalks (higher stalk biomass under the slow-release fertilizer) and/or that metabolic differences (e.g. altered plant water balance, ion transport) led to a reduced root-to-leaf transport of $\mathrm{Cd}$. The above hypotheses need however to be demonstrated. The exact mechanisms by which fertilization regimes and AM affect the Cd uptake by tobacco under different agro-climatic conditions are probably complex and need to be better understood.

\section{ACKNOWLEDGEMENTS}

We thank Marc R. Krauss and Pat Ramey (Philip Morris USA) for their support in the determination of cadmium concentrations, DIMON Inc. (now part of Alliance One International, Inc.) who kindly provided the two soils used in this study, Gregor Bindler (Philip Morris International) who provided the seeds, Matthias Meier (Philip Morris International) and Gernot Alber (Société coopérative pour l'achat du tabac indigène, SOTA) who gave advice on tobacco cultivation, Paolo Donini (Philip Morris International) for helpful discussion during the project, and Luca Rossi (Philip Morris International) for comments on the manuscript. The Research described in this article was supported by Philip Morris International. Moreover, this Research was supported by institutional grants of the Academy of Sciences of the Czech Republic (AVOZ 6005908 and KSK 6005114).

\section{REFERENCES}

1. Heggo, A., J.S. Angle, and R.L. Chaney: Effects of vesicular-arbuscular mycorrhizal fungi on heavy metal uptake by soybeans; Soil Biol. Biochem. 22 (1990) 865-869.

2. Janoušková, M., M. Vosátka, L. Rossi, and N. LugonMoulin: Effects of arbuscular mycorrhizal inoculation on cadmium accumulation by different tobacco (Nicotiana tabacum L.) types; Appl. Soil Ecol. 35 (2007) 502-510.

3. Azcón, R., M. Gomez-Ortega and J.M. Barea: Comparative effects of foliar- or soil-applied nitrate on vesicular-arbuscular mycorrhizal infection in maize; New Phytol. 92 (1982) 553-559.

4. Ryan, M.H., G.A. Chilvers, and D.C. Dumaresq: Colonisation of wheat by VA-mycorrhizal fungi was found to be higher on a farm managed in an organic manner than on a conventional neighbour; Plant Soil 160 (1994) 33-40.

5. Giovannetti, M. and B. Mosse: An evaluation of techniques to measure vesicular-arbuscular infection in roots; New Phytol. 84 (1980) 489-500.

6. Dunnett, C.W.: A multiple comparisons procedure for comparing several treatments with a control; Journal of the American Statistical Association 50 (1955) 1096-1121.

7. Lugon-Moulin, N., L. Ryan, P. Donini, and L. Rossi: Cadmium content of phosphate fertilizers used for tobacco production; Agron. Sustain. Dev. 26 (2006) 151-155.

8. Lugon-Moulin, N., M. Zhang, F. Gadani, L. Rossi, D. Koller, M. Krauss, and G.J. Wagner: Critical review of the science and options for reducing cadmium in tobacco (Nicotiana tabacum L.) and other plants; Adv. Agron. 83 (2004) 111-180.

\section{Corresponding author:}

M. Janoušková

Department of Mycorrhizal Symbioses

Institute of Botany

Academy of Sciences of the Czech Republic

25243 Průhonice

Czech Republic

E-mail: janouskova@ibot.cas.cz 